\title{
Ursolic acid nanoparticles inhibit cervical cancer growth in vitro and in vivo via apoptosis induction
}

\author{
SHAOGUANG WANG, XIAOMEI MENG and YAOZHONG DONG \\ Department of Gynecology, The Affiliated Yantai Yuhuangding Hospital of \\ Qingdao University, Yantai, Shandong 264000, P.R. China
}

Received October 30, 2016; Accepted January 12, 2017

DOI: 10.3892/ijo.2017.3890

\begin{abstract}
Cervical cancer is a cause of cancer death, making it one of the most common causes of death among women globally. Previously, a variety of studies have revealed the molecular mechanisms by which cervical cancer develops. However, there are still limitations in treatment for cervical cancer. Ursolic acid is a naturally derived pentacyclic triterpene acid, exhibiting broad anticancer effects. Nanoparticulate drug delivery systems have been known to better the bioavailability of drugs on intranasal administration compared with only drug solutions. Administration of ursolic acid nanoparticles is thought to be sufficient to lead to considerable suppression of cervical cancer progression. We loaded gold-ursolic acid into poly(DL-lactide-co-glycolide) nanoparticles to cervical cancer cell lines due to the properties of ursolic acid in altering cellular processes and the easier absorbance of nanoparticles. In addition, in this study, ursolic acid nanoparticles were administered to cervical cancer cells to find effective treatments for cervical cancer inhibition. In the present study, ELISA, western blotting, flow cytometry and immunohistochemistry assays were carried out to calculate the molecular mechanism by which ursolic acid nanoparticles modulated cervical cancer progression. Data indicated that ursolic acid nanoparticles, indeed, significantly suppress cervial cancer cell proliferation, invasion and migration compared to the control group, and apoptosis was induced by ursolic acid nanoparticles in cervical cancer cells through activating caspases, p53 and suppressing anti-apoptosis-related signals. Furthermore, tumor size was reduced by treatment of ursolic acid nanoparticles in in vivo experiments. In conclusion, this study suggests that ursolic acid nanoparticles inhibited cervical cancer cell proliferation via apoptosis induction, which could be a potential target for future therapeutic strategy clinically.
\end{abstract}

Correspondence to: Dr Shaoguang Wang, Department of Gynecology, The Affiliated Yantai Yuhuangding Hospital of Qingdao University, Yantai, Shandong 264000, P.R. China

E-mail: zhangying310009@126.com; zhang@126.com

Key words: cervical cancer, ursolic acid nanoparticles, caspases, p53

\section{Introduction}

Cervical cancer is one of the most common cancers in women with an estimated 528,000 new cases each year (1), and approximately 266,000 mortalities caused by cervical cancer in the world, which accounts for $7.5 \%$ of all cancer mortalities related to females (2). Approximately $87 \%$ of the mortalities resulted from cervical cancer in relatively not developed countries and regions. The women, aged from 30 to 50, are more sensitive to cervical cancer due to factors such as gene mutation, or environment, including working stress and emotion (3). Studies related to the molecular mechanisms revealing cervical tumor invasion, metastasis and the novel therapeutic strategies are necessary to suppress cancer progression $(4,5)$.

Pentacyclic triterpenoids show various pharmacological activities, including anti-oxidant, anti-inflammatory and anticancer properties. Pentacyclic triterpenoids have many pharmacological functions, including anti-inflammation effect, antioxidant activity, hepatoprotective and antitumor activity (6-8). In addition, the plant-derived chemicals ameliorating diseases progression have gained increasing attention. Pentacyclic triterpenoids, such as imberbic acid, betulinic acid, zeylasteral and ursolic acid have been reported to have anticancer effect $(9,10)$. As a pentacyclic triterpene acid, ursolic acid has a number of pharmacological effects, such as antioxidative (11), antifungal, antibacterial, anti-inflammatory, antiangiogenic, anti-mutagenic, anticarcinogenic, anti-viral, anti-atherosclerotic, antitumor, hepatoprotective, as well as anti-hyperlipidemic activity (12-16). Ursolic acid is also known to enhance apoptotic response in various human cancer cell lines (17). However, there are limited reports involving the key role of ursolic acid in regulating cervical cancer progression.

Use of nanoparticles in cancer treatment has been widely investigated. The special features of nanoparticles can improve the defects in the use of small molecules as therapeutic agents in biomedical applications $(18,19)$. For instance, the uptake of medicine may be promoted by the 'enhanced permeability and retention effect', enhancing the medicine accumulation in the target cancer part and decrease the efflux pump-regulated drug resistance (20). In addition, capsuled by different nanoparticles, the solubility and the half-life of small molecular drugs could be improved with the controllable releasing behavior (21). To increase ursolic acid biocompatibility and water solubility, drug nanocarriers are developed according to nanotechnology. 
Additionally, the slow and controlled release of the drug helps to provide a sustainable dose at the therapeutic level, which is helpful to improve efficiency and safety (22-24). In the present study, we developed PLGA nanoparticles as biodegradable and biocompatible carriers for loading and delivery of the binary drug ursolic acid, which displayed an excellent anticancer performance in vitro and in vivo.

\section{Materials and methods}

Cell treatment. Human cervical cancer cell lines, including CaSki, HeLa, C4-1 and SiHa, were obtained from the American Type Culture Collection (ATCC; Rockville, MD, USA). The cell lines of 293 T and L02 were also obtained from ATCC. All the cells were maintained in RPMI-1640 medium containing $10 \%$ fetal bovine serum (FBS) and $1 \%$ penicillin/ streptomycin (Gibco-BRL/Life Technologies) at $37^{\circ} \mathrm{C}$ with a humidified incubator in $5 \% \mathrm{CO}_{2}$ atmosphere. The cells were treated with different concentrations of ursolic acid nanoparticles for different time as shown in the figures.

Ursolic acid nanoparticle preparation. High performance liquid chromatography (HPLC)-grade ursolic acid was obtained (>98\%; NanoBiotech, Co., Shanghai, China) in anhydrous powder form. AuNPs were obtained by downregulated $1 \mathrm{mM}$ gold chloride with a freshly ready-made ursolic acid solution in alcohol. The yellow color solution changed to deep red as the ursolic acid nanoparticles were finished. A total of $50 \mathrm{mg}$ poly(lactic-co-glycolic acid) (PLGA) was added to an AuNPs water dispersion. Next, the mixture drops were added to $20 \mathrm{ml}$ of an aqueous solution with a stabilizer (1\% polyoxyethylene-polyoxypropylene; F68). The mixture drops were mixed at $500 \mathrm{rpm}$ and $4{ }^{\circ} \mathrm{C}$ until the alcohol had evaporated completely. Washing and centrifugation were performed again $\left(25,000 \times \mathrm{g}, 4^{\circ} \mathrm{C}\right.$ for $\left.30 \mathrm{~min}\right)$, in order to remove redundant stabilizer completely. The pellet was then resuspended in Milli-Q water. The ursolic acid nanoparticles were stored at $4^{\circ} \mathrm{C}$ for further study. Fluorescent dye was conjugated to the gold surface by adding FITC dye to the PLGA and ursolic acid nanoparticles mixture, which were performed in the dark. In addition, scanning transmission electron microscopy (SEM) (FEI Quanta 650; FEI Co., Hillsboro, OR, USA) was used to determine naked quercetin nanoparticles size. Furthermore, dynamic light scattering (DLS) with LB-550 DLS particle size analyzer (Horiba Scientific, Edison, NJ, USA) was used to examine the average size of ursolic acid nanoparticles. We analyzed the data in the automatic mode. Twenty runs of size were determined, with triplicate measurements for each run. We measured the zeta potential of the ursolic acid nanoparticles in the same instrument using the same procedure.

MTT assay. MTT method was used to analyze the cell viability. The culture medium was totally removed and $5 \mu \mathrm{l}$ MTT (Sigma-Aldrich, St. Louis, MO, USA) solution $(10 \mathrm{mg} / \mathrm{ml})$ was added to $100 \mu \mathrm{l}$ of phenol red-free growth medium and plates were incubated at $37^{\circ} \mathrm{C}, 5 \% \mathrm{CO}_{2}$ cell culture environment. Mitochondrial decrease of MTT develops formazan crystals after dissolving in dimethyl sulfoxide (DMSO). Afterwards, microplate reader (Bio-Rad Laboratories, Hercules, CA, USA) was used to measure absorbance of each well at $540 \mathrm{~nm}$.
Colony-forming assay. Cervical cancer cells were suspended in $0.9 \%$ methylcellulose-based semisolid medium MethoCult H4100 (Stem Cell, Beijing, China). Individual primary clones (450 cells) after 15 days were trypsinized and re-plated in the same conditions to test the secondary colony forming ability for self-renewal.

Migration and invasion assays. Matrigel (2 $\mu \mathrm{g} / \mathrm{well}$; BD Biosciences, San Jose, CA, USA) was used to pre-coat 24-well plates with $8-\mu \mathrm{m}$ pore size polycarbonate membrane (Millipore, Bedford, MA, USA) for invasion assays. Cells under different conditions (exposure to different concentrations of drugs for 48 h). Cells $\left(1.0 \times 10^{5}\right)$ were seeded on the upper chamber with serum-free DMEM $(200 \mu \mathrm{l})$. DMEM $(1 \mathrm{ml})$ with $30 \%$ serum was added to the lower chamber. After $16 \mathrm{~h}$, cell migration or invasion (plates coated with Matrigel) was terminated and the membranes were fixed with $4 \%$ paraformaldehyde and stained with crystal violet. Five visual fields were randomly selected from each membrane, and the cell numbers were counted via a light microscope. All experiments were performed in triplicate.

Establishment of xenograft tumor models. Forty male, 6-8-weeks old athymic nude mice were purchased from the Shanghai Experimental Animal Center (Shanghai, China) and were kept in a temperature and humidity-controlled environment $\left(25 \pm 2^{\circ} \mathrm{C}, 50 \pm 10 \%\right.$ humidity $)$ with a standard 12-h light and dark cycle with food and water in cages under the germfree conditions. CaSki, SiHa and HeLa cells $\left(1 \times 10^{7}\right)$ were suspended in $100 \mu \mathrm{l}$ serum-free medium and injected subcutaneously into the left flank of nude mice. Then, the animal models were treated with ursolic acid (10 and $20 \mathrm{mg} / \mathrm{kg}$ ). The mice were divided into two groups. Animals in the control group were treated with sterile DMSO via intraperitoneal injection for five days. Animals in ursolic acid-treated group were intraperitoneally administered with $20 \mathrm{mg} / \mathrm{kg}$ ursolic acid nanoparticles for five days, respectively. Tumor size was measured with digital caliper and calculated twice a week for 5 weeks. Then, the mice were sacrificed. Tumors were excised, weighted, fixed in $10 \%$ neutral formalin, and embedded in paraffin for histological analysis. Ethics approval was obtained from the Department of Gynecology, The Affiliated Yantai Yuhuangding Hospital of Qingdao University.

Western blot analysis. After treatments under different conditions, the cells were harvested and the medium was removed. Then, the cells were washed with chilled phosphate-buffered saline (PBS) three times and lysed in ice-cold lysis buffer in the presence of fresh protease inhibitor cocktail. Frozen lung tumor tissue samples were obtained from xenograft nude mice after treatments. Approximately a $100 \mathrm{mg}$ tumor tissue sample was lysed with $1 \mathrm{ml}$ lysis buffer. The cell lysates were centrifuged at $15,000 \mathrm{xg}$ for $15 \mathrm{~min}$ at $4^{\circ} \mathrm{C}$ to collect the supernatant. BSA protein assay kit was used to detect the protein concentrations following the manufacturer's instruction (Thermo Fisher Scientific, Waltham, MA, USA). A total of $40 \mathrm{ng}$ of protein extracts were separated by $10 \%$ SDS-PAGE and were then transferred to polyvinylidene fluoride membrane (PVDF) (Millipore). The PVDF with proteins were blocked with 5\% skim fat dry milk in $0.1 \%$ Tween-20 in Tris-buffered saline (TBS) for $2 \mathrm{~h}$ to block the non-specific sites on blots. The 

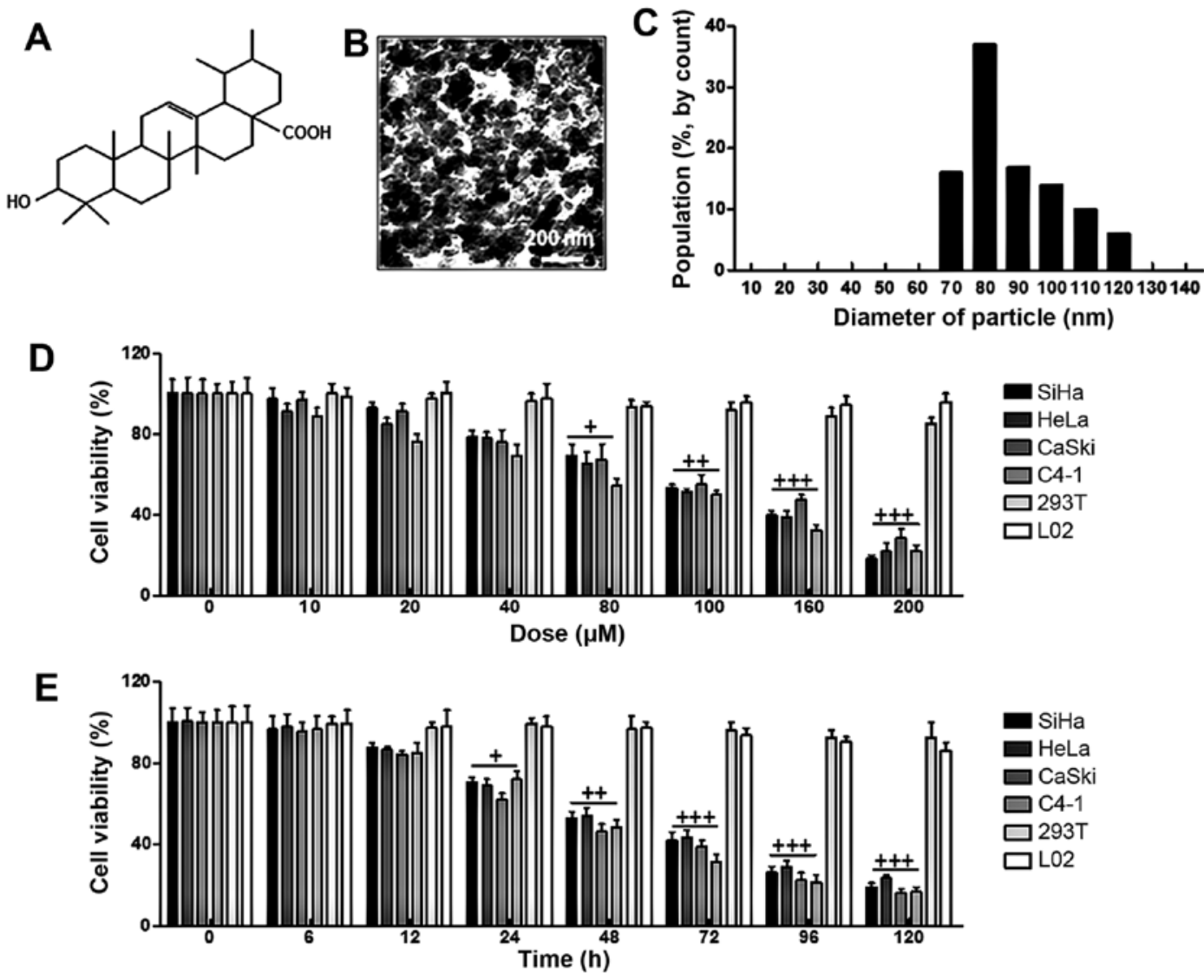

Figure 1. The effects of ursolic acid nanoparticles on cell growth and proliferation. (A) The chemical structure of ursolic acid. (B) The electron micrograph of ursolic acid acid. (C) The average particle size obtained from the nanoparticle DLS data. (D) Percentage of cell viability: 0-200 $\mu$ M ursolic acid nanoparticles was added to different cervical cancer and cell line cultures for $48 \mathrm{~h}$. Cell viability was calculated by the MTT analysis, and the graph dispalyed a gradual downregulation in cervical cancer cell viability. (E) Percentage of cell viability: $100 \mu \mathrm{M}$ ursolic acid nanoparticles was added to different cervical cancer and normal cell line cultures for different time. Cell viability was calculated by the MTT analysis, and the graph dispalyed a gradual downregulation in cervical cancer cell viability. Each value represents the mean $\pm \mathrm{SE} .{ }^{+} \mathrm{P}<0.05,{ }^{++} \mathrm{P}<0.01$ and ${ }^{+++} \mathrm{P}<0.001$ compared to control group.

primary antibodies dissolved in blocking buffer were used to detect the target protein blots at $4^{\circ} \mathrm{C}$ overnight for incubation. The bands on PVDF were covered by chemiluminescence with Pierce ECL Western Blotting Substrate reagents (Thermo Fisher Scientific). All experiments were performed in triplicate and carried out three times independently. The primary antibodies are as follows: Bcl-2 (1:1,000; Abcam, Cambridge, MA, USA), Bax (1:1,000; Abcam), caspase-3 (1:1,000; Cell Signaling Technology, Beverly, MA, USA), caspase- 8 (1:1,000; Cell Signaling Technology), caspase-9 (1:1,000; Cell Signaling Technology) and GAPDH (1:500; Cell Signaling Technology).

Immunofluorescence assays. After induction by conditioned culture medium, the different cells were fixed in $4 \%$ paraformaldehyde, permeabilized with $0.1 \%$ Triton X-100 in PBS containing $0.5 \%$ BSA (PBS-BSA) for $30 \mathrm{~min}$. The cells were subsequently incubated with caspase- 3 for $30 \mathrm{~min}$, followed by labeling with Alexa Fluor 488-conjugated rabbit anti-mouse or goat anti-rabbit IgG antibody. The cells were viewed under a fluorescence microscope.

Histopathologic examination of tissues. After harvesting, the xenograft tumors were fixed in formalin and embedded in paraffin. Five micrometer sections of these tumors were deparaffinized in xylene and then hydrated through a series of xylene and ethanol washes. Sections were incubated in a citrate buffer ( $\mathrm{pH} \mathrm{6.0)}$ ) for $30 \mathrm{~min}$ at $95^{\circ} \mathrm{C}$ for antigen retrieval. After blocking, sections were incubated overnight with appropriate dilatation of primary antibodies (p53 and Bcl-2; Cell Signaling Technology) followed by incubation with a secondary antibody and analyzed for staining as previously described (25). Then the samples were observed under a microscope.

Statistical analysis. Data are expressed as means \pm SEM. Treated cells, tissues and the corresponding controls were compared using GraphPad Prism (version 6.0; GraphPad Software, La Jolla, CA, USA) by a one-way ANOVA with Dunn's least significant difference tests. Differences between groups were considered significant at $\mathrm{P}<0.05$.

\section{Results}

The effects of ursolic acid nanoparticles on cell growth and proliferation. From Fig. 1B, the surface morphology of ursolic acid nanoparticles was studied under SEM. The image displayed spherically shaped ursolic acid nanoparticles with a smooth surface without pinholes or cracks. In addition, DLS data indicated that the mean ursolic acid nanoparticle 
A

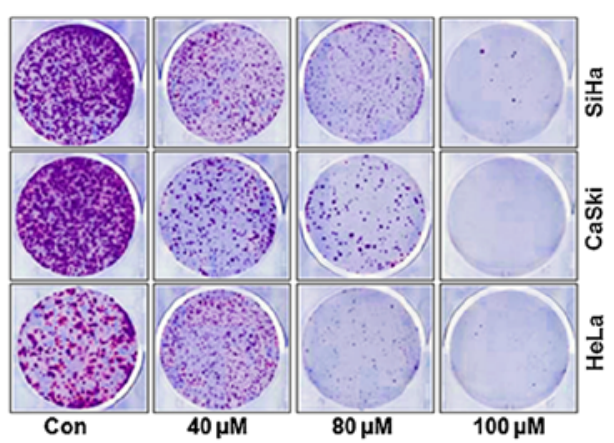

C

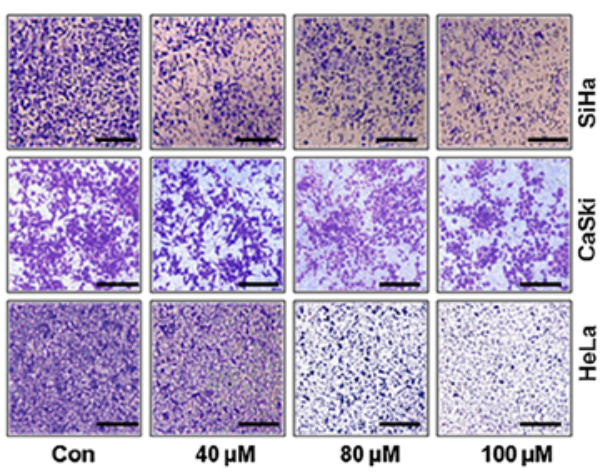

E

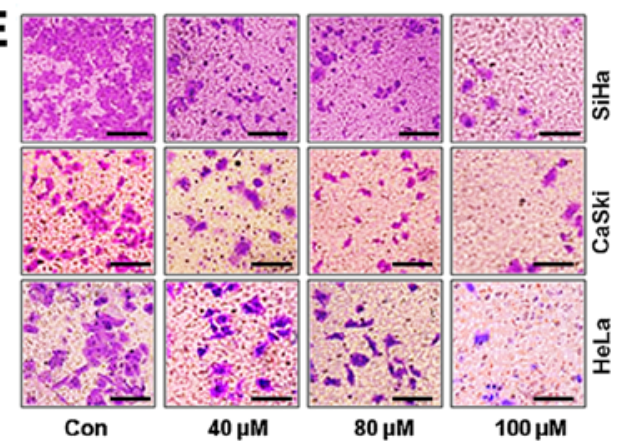

B

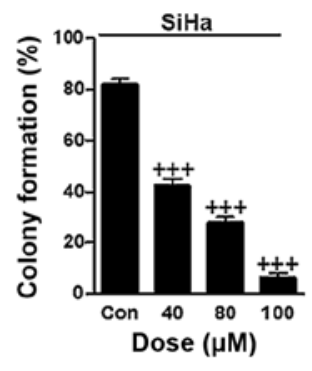

D

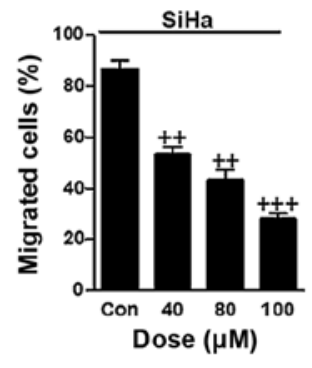

F

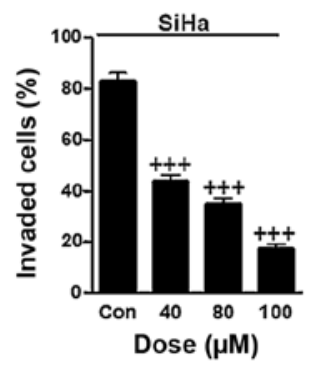

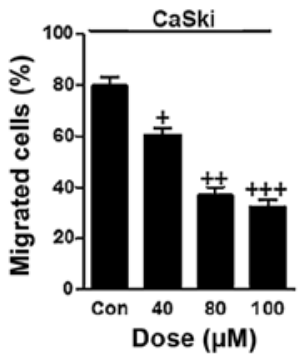
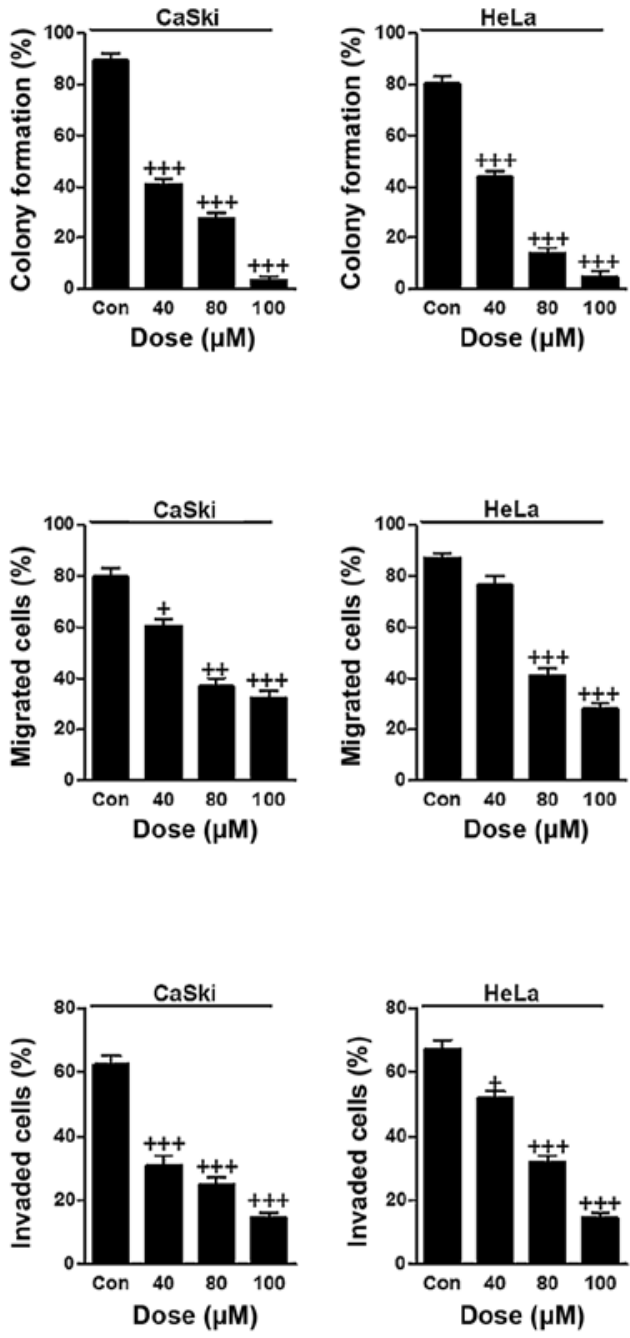

Figure 2. Ursolic acid nanoparticles effectively suppressed cervical cancer cell proliferation, migration and invasion. (A) The colony formation analysis of cervical cancer cell lines. (B) The quantification of colony formation is shown. (C) The representative images of migrated cervical cancer cells across a Transwell chamber are shown in both cell lines. (D) The quantification of the number of migrated cervical cancer cells. (E) The representative images of the invaded cervical cancer cells across a Transwell chamber are shown in both cell lines. (F) The quantification of the invaded cervical cancer cells. Each value represents the mean $\pm \mathrm{SE} .{ }^{++} \mathrm{P}<0.01$ and ${ }^{+++} \mathrm{P}<0.001$ compared to control group.

diameter was $80 \mathrm{~nm}$ (Fig. 1C). Furthermore, in this study, four cervical cancer cell lines and the other two cell types from different origins were selected to calculate whether ursolic acid nanoparticles were specific. As shown in Fig. 1D, we found that ursolic acid nanoparticles reduced cell viability after $48 \mathrm{~h}$ in various cancer cell lines, which was shown in a dose-dependent manner, especially over $40 \mu \mathrm{M}$. Notably, in cells of 293T and L02, no alterations in cell viability were observed. Next, the cell viability was further explored at the concentration of $160 \mu \mathrm{M}$ ursolic acid nanoparticles from 0 to $120 \mathrm{~h}$. Ursolic acid nanoparticles obviously decreased the viability of cancer cells in a time-dependent manner. Similarly, no significant difference was detected in normal cells of $293 \mathrm{~T}$ and L02 (Fig. 1E). Taken together, the data above indicated that ursolic acid nanoparticles had an inhibitory role in cervical cancer cell proliferation, which was in a dose- and time-dependent manner without cytotoxicity to normal cells, suggesting that ursolic acid nanoparticles might be effective in controlling cervical cancer progression.
Ursolic acid nanoparticles effectively suppressed proliferation, migration and invasion in cervical cancer cells. In this regard, we attempted to evaluate how ursolic acid nanoparticles influenced cervical cancer cells proliferation, migration and invasion. The colony formation analysis indicated that ursolic acid nanoparticles had an inhibitory role in suppressing colony formation in cervical cancer cells of $\mathrm{SiHa}, \mathrm{CaSki}$ and HeLa in a dose-dependent manner with significant difference (Fig. 2A and B). In addition, the percentage of migrated cervical cancer cells was also reduced apparently after different concentrations of ursolic acid nanoparticle treatment (Fig. 2C and D). Finally, the invasion of cervical cancer cells was evaluated, and the results showed that the number of invaded cells was reduced significantly by the use of ursolic acid nanoparticles (Fig. 2E and F). In conclusion, the data above suggested that ursolic acid nanoparticles could suppress cervical cancer progression by suppressing the proliferation, migration and invasion of cervical cancer cells. 
A
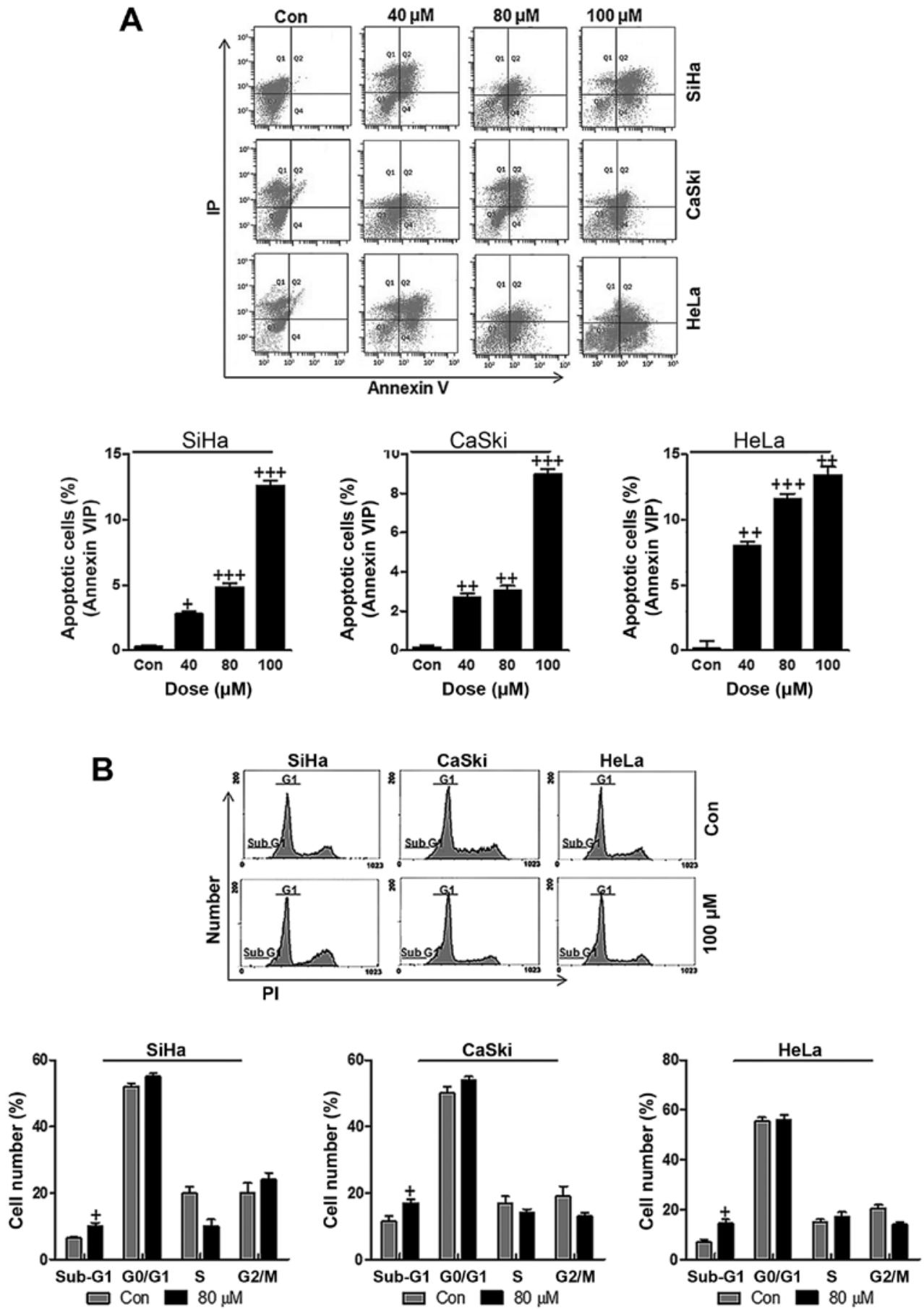

Figure 3. The effects of ursolic acid nanoparticles on apoptosis in the cervical cancer cell lines via flow cytometry assays. (A) Flow cytometry was performed to determine the number of apoptotic cells in SiHa, CaSki and HeLa cancer cell lines. (B) Ursolic acid nanoparticle-induced apoptosis showed as sub-G1 population evaluated through flow cytometry in $\mathrm{SiHa}, \mathrm{CaSki}$ and $\mathrm{HeLa}$ cancer cell lines. Each value represents the mean $\pm \mathrm{SE} .{ }^{+} \mathrm{P}<0.05,{ }^{++} \mathrm{P}<0.01$ and ${ }^{+++} \mathrm{P}<0.001$ compared to control group.

The effects of ursolic acid nanoparticles on apoptosis in the cervical cancer cell lines via flow cytometry assays. Apoptosis is well known to be of great importance in suppressing cancer progression through inducing cell death $(26,27)$. In order to calculate whether ursolic acid nanoparticles could perform its effects on cervical cancer suppression, flow cytometric analysis was performed to confirm our hypothesis. As shown in Fig. 3A, different concentrations of ursolic acid nanoparticles were administered to cervical cancer cells, SiHa, CaSki and HeLa. Consistently, ursolic acid nanoparticle treatment significantly accelerated apoptosis in cervical cancer cell lines, especially at the highest concentration of $100 \mu \mathrm{M}$ in comparison to the control groups. Also, cell cycle arrest showed that the number of cells in the Sub-G1 phase was higher after $100 \mu \mathrm{M}$ ursolic acid nanoparticle treatment compared to the control group in the three cervical cancer cell lines, suggesting that apoptosis was induced for ursolic acid nanoparticles, which was in agreement with the above apoptotic results (Fig. 3B). In summary, the data above indicated that ursolic acid nanoparticles could, at least partly, 
A
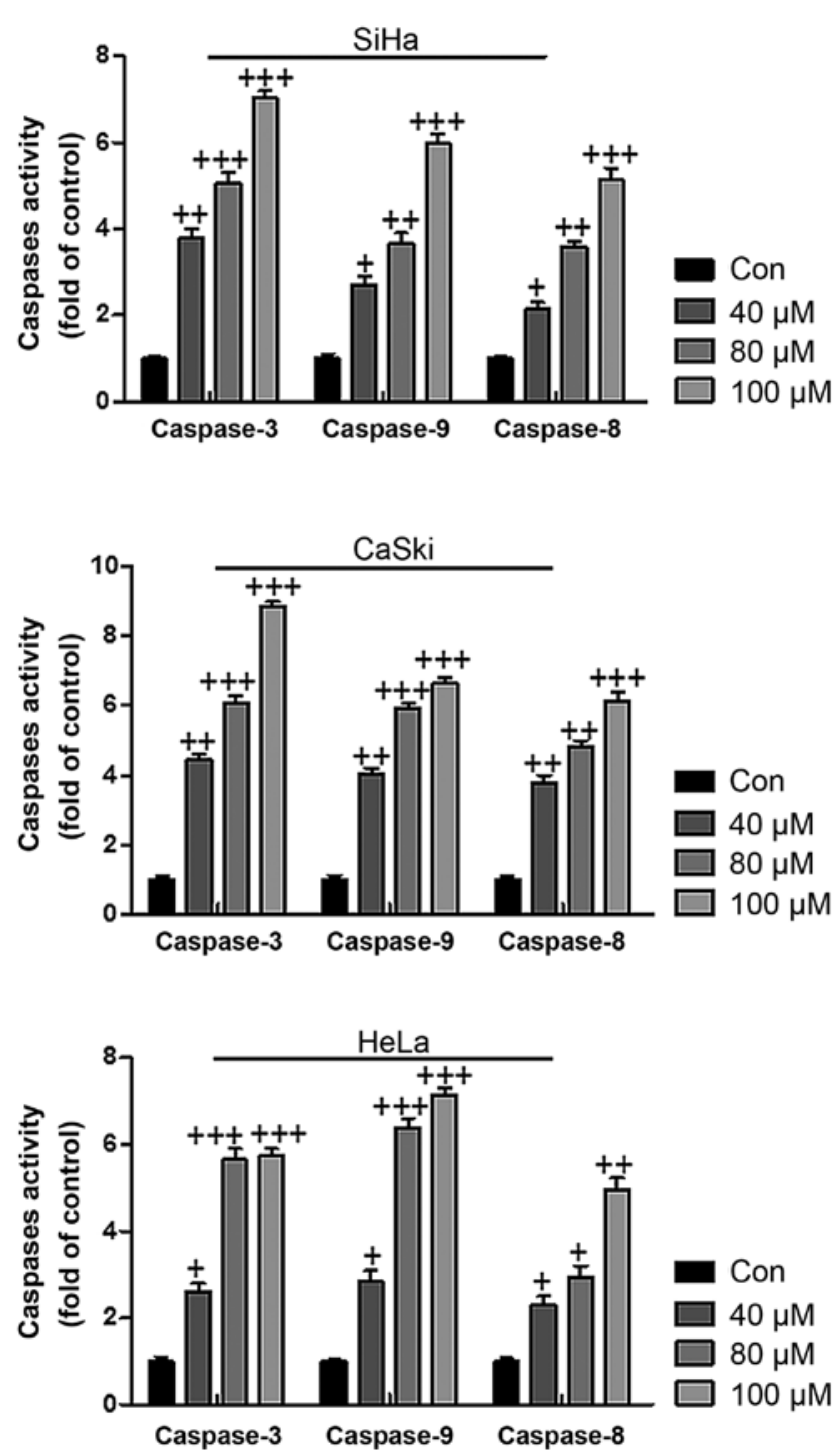

B

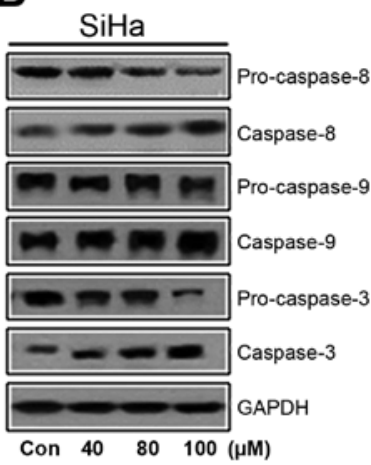

CaSki

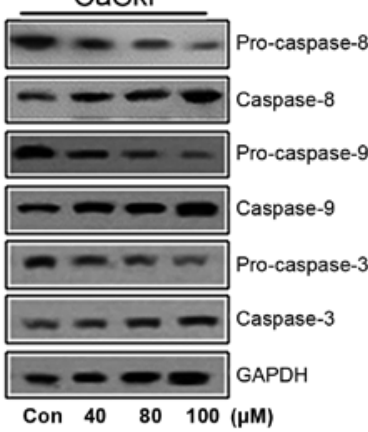

HeLa

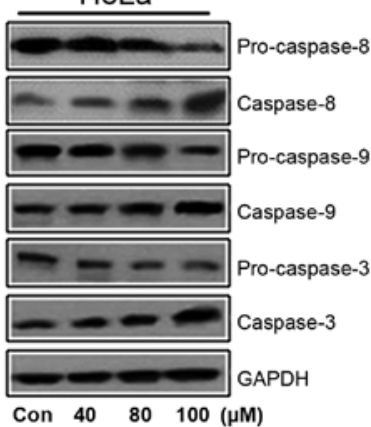

Figure 4. Effect of ursolic acid nanoparticles on apoptosis induction through caspase regulation. (A) Caspase-3, caspase-9 and caspase-8 activities were measured in the SiHa, CaSki and HeLa cancer cell lines. (B) Ursolic acid nanoparticles induced apoptosis in cervical cancer cell lines through caspases activation through western blot analysis. Each value represents the mean $\pm \mathrm{SE} .{ }^{+} \mathrm{P}<0.05,{ }^{++} \mathrm{P}<0.01$ and ${ }^{+++} \mathrm{P}<0.001$ compared to control group.

suppress cervical cancer progression and development through inducing apoptosis.

Effect of ursolic acid nanoparticles on apoptosis induction through caspase regulation. As mentioned above, apoptosis has been investigated in connection to cervical cancer cell death. According to previous reports, caspases play an essential role in modulating apoptosis (28). Therefore, western blot analysis was used to explore whether caspase activity participated in apoptosis in the present study. As shown in Fig. 4A, caspase-3, caspase- 9 and caspase- 8 were analyzed through ELISA. Compared to the control group, we found that caspase-3, caspase- 9 and caspase- 8 were highly expressed in $\mathrm{SiHa}$ cells after ursolic acid nanoparticle administration, further indicating that apoptosis was induced (Fig. 4A). In line with the results in $\mathrm{SiHa}$ cells, caspase-3, caspase-9 and caspase- 8 were overexpressed in CaSki and HeLa cells treated with ursolic acid nanoparticles (Fig. 4A). To further prove that caspases were activated in cervical cancer cells after ursolic acid nanoparticles treatment, western blot assays were performed to show how caspase-3 and caspase- 9 changed. In Fig. 4B, we found that the caspase- 8 , caspase- 3 and caspase- 9 were expressed highly, while the pro-caspase- 8 , pro-caspase- 9 and pro-caspase-3 were reduced after ursolic acid nanoparticles treatment in a dose-dependent manner, contributing to apoptosis in cervical cancer cells. The results here indicated that ursolic acid nanoparticle treatment induced apoptosis in cervical cancer cells.

Effect of ursolic acid nanoparticles on apoptosis formationrelated gene and protein expression in SiHa, CaSki and HeLa cancer cell lines. p53 is known to be closely related to cell proliferation and apoptosis (29). In this regard, immunofluorescence analysis was used first to calculate p53 alteration in SiHa, CaSki and HeLa cells after $100 \mu \mathrm{M}$ ursolic acid nanoparticle treatment. As shown in Fig. 5A, higher expression 
A

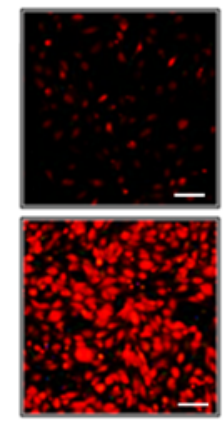

$\mathrm{SiHa}$
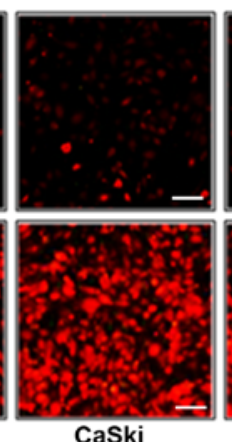

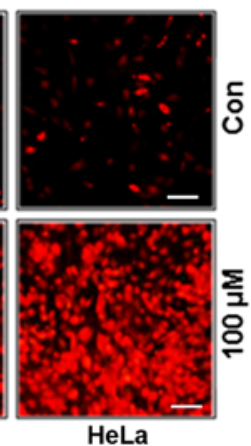

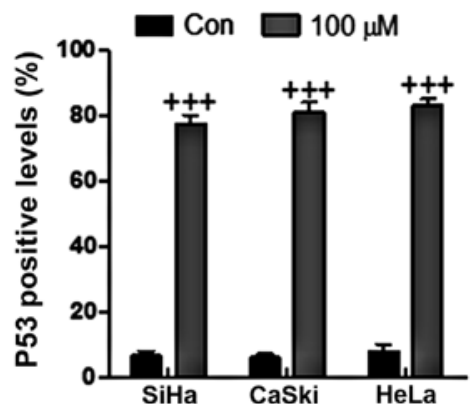

B
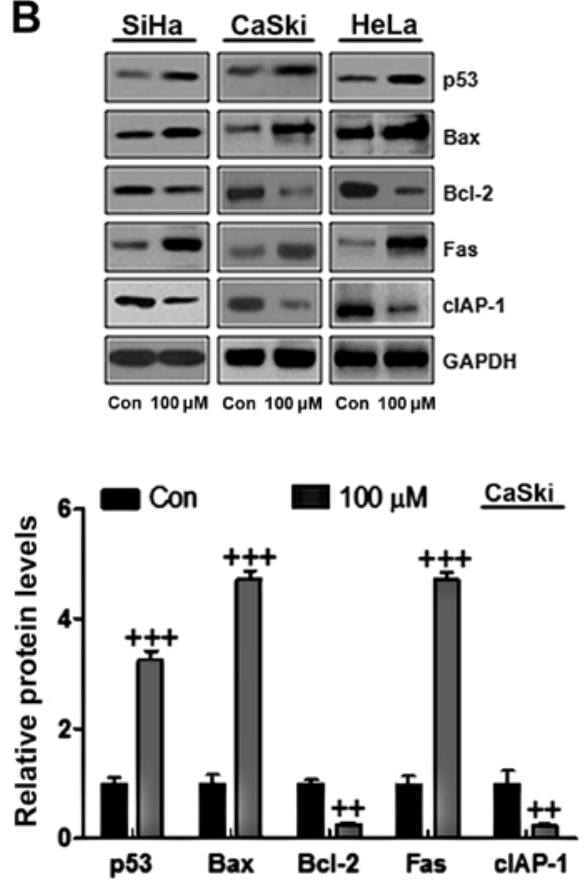
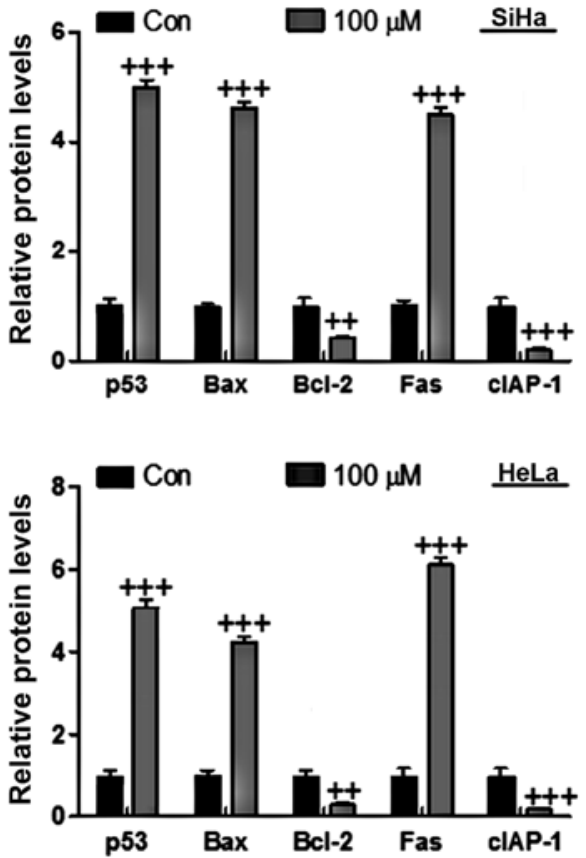

Figure 5. Effect of ursolic acid nanoparticles on apoptosis-related gene and protein expression in SiHa, CaSki and HeLa cancer cell lines. (A) Immunofluorescent analysis was used to determine p53 levels in SiHa, CaSki and HeLa cancer cell lines. (B) An increase in p53, Bax and Fas, and a decrease in Bcl-2 amd cIAP-1 protein levels in SiHa, CaSki and HeLa cancer cell lines via western blot analysis. Each value represents the mean $\pm \mathrm{SE}$. ${ }^{++} \mathrm{P}<0.01$ and ${ }^{+++} \mathrm{P}<0.001$ compared to control group.

of p53 was observed in cervical cancer cells in comparison to the control ones, suggesting that ursolic acid nanoparticles upregulated p53 levels. The protein analysis by western blot showed that the p53 and other four apoptosis-related proteins were changed in SiHa, CaSki and HeLa cells treated with ursolic acid nanoparticles for $48 \mathrm{~h}$. The tested compound caused an increase in the level of p53, Bax and Fas proteins significantly, which was similar to a decrease in Bcl-2 and cIAP-1 protein expression in SiHa, CaSki and HeLa cells (Fig. 5B). Together, the data above illustrated that ursolic acid nanoparticles suppressed cervical cancer cell development and progression via p53 and apoptosis-related signals modulation.

Ursolic acid nanoparticles suppressed cervical cancer growth and progression in a mouse xenograft model. In order to further confirm the inhibitory role of ursolic acid nanoparticles in cervical cancer progression, a mouse xenograft model was used in in vivo experiments. From Fig. 6A, we found that the tumor volume in SiHa-induced xenograft mice was downregulated significantly compared to the control group after ursolic acid nanoparticles administration. However, no remarkable alteration of the mouse body weight was observed here, suggesting that ursolic acid nanoparticles might be of little toxicity to animals. Consistent with the results above, the volume of tumor in CaSki- and HeLa-induced mice was also reduced significantly in comparison to the control ones. Also, there was no remarkable alteration in the weight of animals (Fig. 6). The data here suggested that ursolic acid nanoparticles, at least partly, had an effective role in suppressing cervical tumor progression and development in vivo.

Ursolic acid nanoparticles suppressed cervical cancer growth through apoptosis-related genes. The results mentioned above (Fig. 5) in vitro showed that p53 and Bcl-2 were associated with cervical tumor growth, which could be regulated by ursolic acid nanoparticle administration. In in vivo studies, immunohistochemical analysis elucidated that ursolic acid 


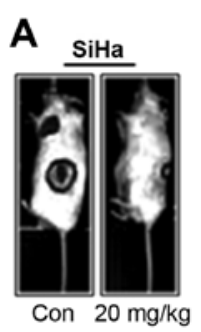

B

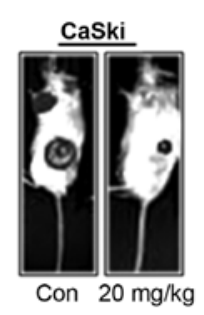

C

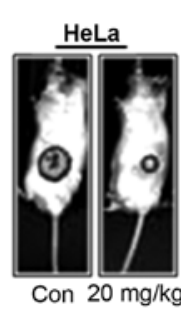

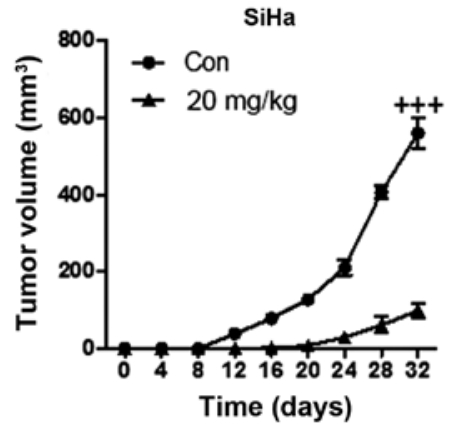

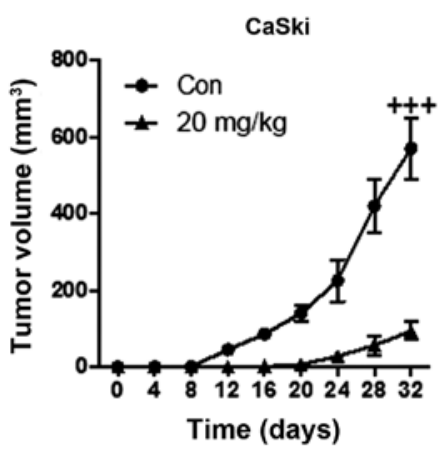

HeLa

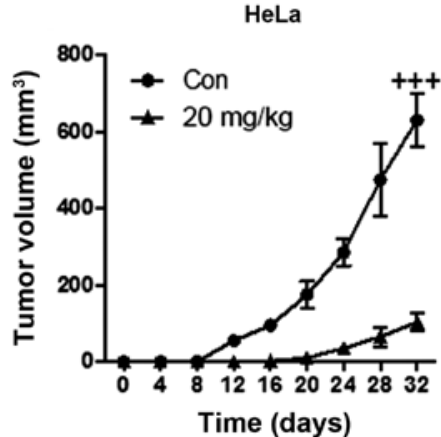

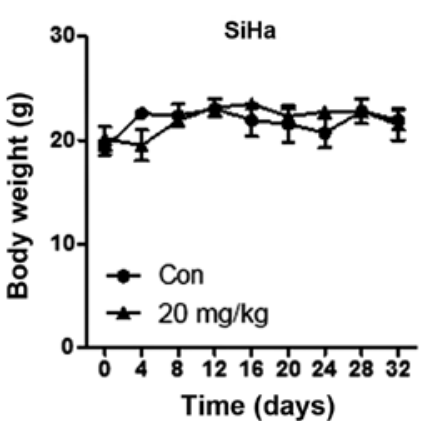
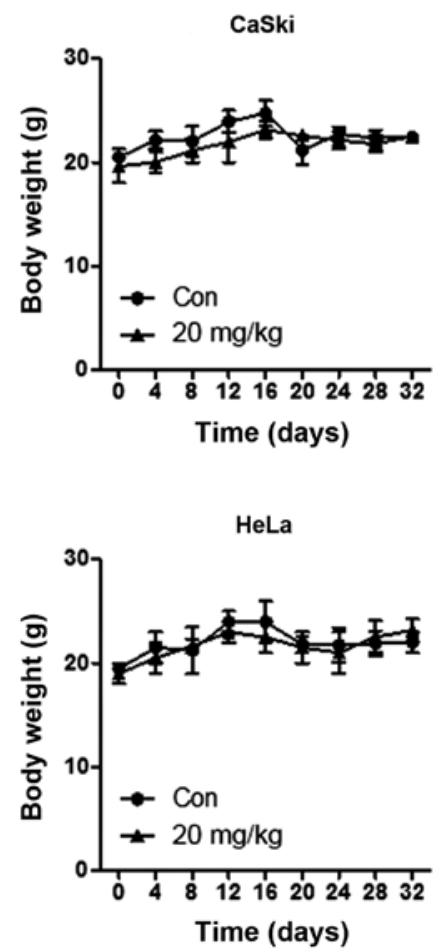

Figure 6. Ursolic acid nanoparticles suppressed cervical cancer growth and progression in a mouse xenograft model. Images of the (A) SiHa, (B) CaSki and (C) HeLa-induced tumor-bearing mice treated with or without ursolic acid nanoparticles. The percentage of tumor growth and body weight during the whole time period of the study were calculated. Each value represents the mean $\pm \mathrm{SE} .{ }^{+++} \mathrm{P}<0.001$ compared to control group.

nanoparticle treatment significantly upregulated p53 expression in cervical cancer cells compared to the control ones (Fig. 7A). By contrast, Bcl-2, as mentioned above, is an anti-apoptotic factor, which was reduced after administration of ursolic acid nanoparticles, suggesting that ursolic acid nanoparticles could induce cervical cancer cell death through inhibiting the expression of anti-apoptotic factors (Fig. 7B). Finally, we also determined how the survival rate changed in animal models with cervical cancer after ursolic acid nanoparticles treatment. As shown in Fig. 7C, the survival rate was higher in mice after the treatment of ursolic acid nanoparticles. The data indicated that the survival rate of SiHa-, CaSki- and HeLa-induced animal models with cervical tumor was increased.

\section{Discussion}

Cervical cancer is one of the leading causes for gynecologic cancer death among women worldwide and approximately 528,000 new cervical cancer patients are deduced, resulting in
266,000 deaths every year (30). Over $80 \%$ of cervical cancer cases are diagnosed in developing countries $(31,32)$. In addition, new cases suffering from cervical cancer are up 150,000 in China each year, accounting for approximately $30 \%$ of new cases across the world. Although a large number of cervical cancer patients benefit from neoadjuvant chemotherapy with concurrent chemotherapy and radiotherapy, currently the survival rate still remains poor among cervical cancer patients (33). Resistance to chemotherapy has been reported as a common reason of treatment failure in patients with cervical cancer (34).

Ursolic acid, a pentacyclic terpenoid, exhibits a wide and powerful pharmaceutical activities (35). Ursolic acid is reported as a secondary plant metabolite, often found in the leaves, stem bark or fruit peel (36). The promoting activities for health of this compound have been used for centuries, which is an ingredient of herb extracts involved in folk medicine. Finding natural biologically active substances, has come back to this source of knowledge acquired over generations $(37,38)$. Furthermore, ursolic acid is one of the most 

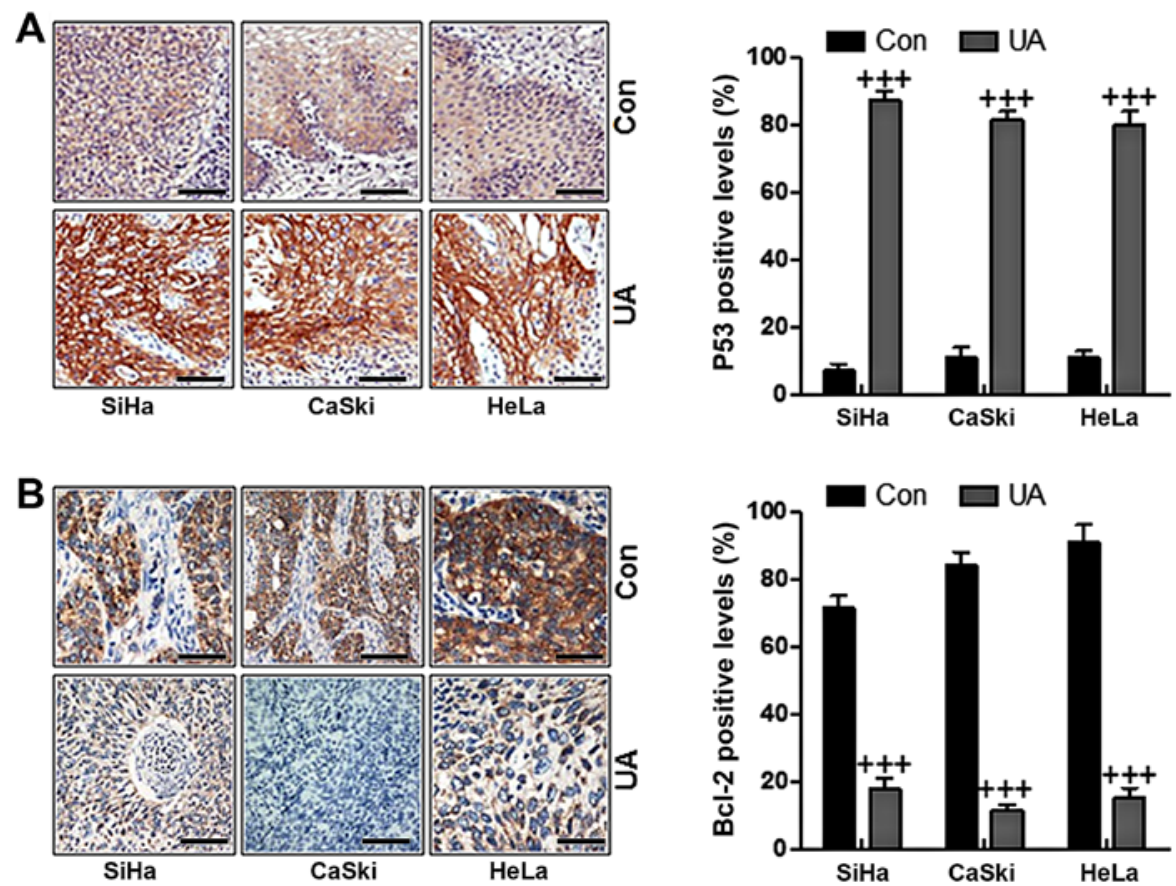

C

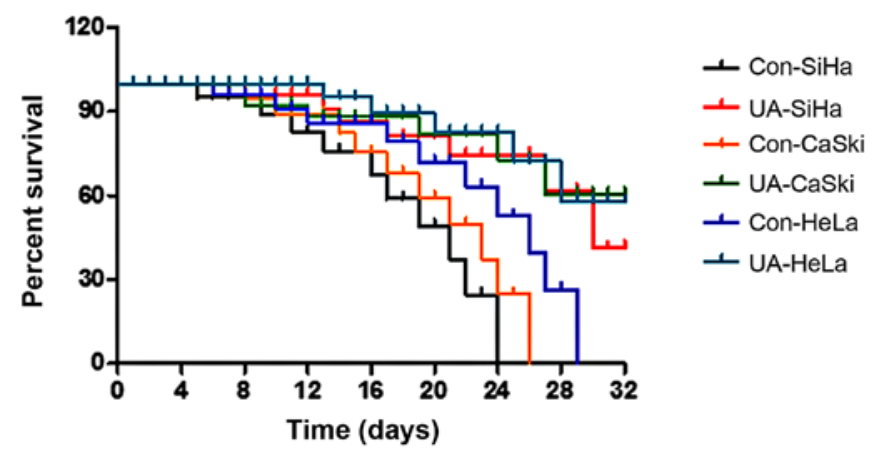

Figure 7. Ursolic acid nanoparticles suppress cervical cancer growth through apoptosis-related genes. The expression levels of (A) p53 and (B) Bcl-2 were examined via immunohistochemistry analysis in tumor tissue samples from the mice. Representative images are displayed (left panel). The quantitative analysis in histograms (right panel) is shown. (C) The calculation of the survival rate of each group was determined. Each value represents the mean \pm SE. ${ }^{++} \mathrm{P}<0.001$ compared to control group.

promising substances of biological origin when it is used for the prevention and therapy of tumors (36). New pharmacological strategies not only rely on the termination of cancer cells, but also regulate their metabolism to restrain angiogenesis and metastasis, promote cancer cell differentiation and protect normal and healthy tissue from inflammation and oxidative stress $(39,40)$. The anticancer activity of ursolic acid is related to its ability to influence the activity of several enzymes. Thus, it is able to regulate processes inside tumor cells, leading to cell death often by apoptosis and inhibition resulting in proliferation, growth and migration of tumors $(41,42)$. The effective and successful application of liposome nanocarriers has been catalyzed through targeted delivery and subsequent preferential intracellular uptake, enhancing permeability and retention effect with enhanced selectivity, efficacy, as well as overall safety (43-45).

In this study, we found that ursolic acid nanoparticles showed inhibitory role in cervical cancer progression, while no toxicity was observed to cells 293T and L02, suggesting that ursolic acid nanoparticles indeed inhibit cervical cancer development, which could be a potential therapeutic strategy for patients in future. Furthermore, the colony formation assay indicated that ursolic acid nanoparticles suppressed cervical cancer cell proliferation significantly. In addition, the migration and invasion analysis also suggested that ursolic acid nanoparticles showed inhibitory role in cervical cancer cell lines.

Apoptosis normally occurs during the development to homeostasis in normal cells and tissues or occurs as a defense mechanism to eliminate the defective or unwanted cells selectively damaged by disease (46-48). It has been reported as a necessary complementary to inhibit cell proliferation and plays an important role in the development and regulation of immune system, the removal of damaged cells, and furthermore, the apoptosis disruption is involved in tumor development (49). In the present study, flow cytometric analysis indicated that ursolic acid nanoparticles induced apoptosis, leading to cell death during cervical cancer progression. Additionally, the number of cells in sub-G1 was also higher in cervical cancer cells treated by ursolic acid nanoparticles, which further suggested that ursolic acid nanoparticles induced apoptosis in cervical cancer to suppress cervical cancer development. 
Caspases were further examined for their activity to regulate signal transduction by positively or reversely regulating kinases, phosphatases and other signal molecules in cells (50). Considering the well-characterized effect of caspase-3, an important apoptosis regulator in both extrinsic and intrinsic pathways, attention on its pro-apoptotic ability has increased (51-54). In this study, we found that caspase-3, caspase- 9 and caspase- 8 were upregulated in ursolic acid nanoparticletreated cervical cancer cells, suggesting that ursolic acid nanoparticles induced cervical cancer cell death via apoptosis induction through activating caspases.

Cell signal pathways when they are de-regulated, relate to apoptosis and cell cycle, and have a significant role in the development and progression of diseases, including cancer. The members of p53 family are known as significant players responding to the cellular stress in cancer and, thus, these genes may act as therapeutic targets (55). Cellular stress, such as DNA damage, ribosomal and endoplasmic reticulum stress, stimulates p53 activity while it is strictly maintained at low levels under normal conditions (56). The cell cycle arrest and apoptosis are two main molecular mechanisms, regulating response of p53 to the DNA damage (57). Here, we found that p53 was upregulated in cervical cancer cells treated by ursolic acid nanoparticles, helping to promote apoptosis, which was in agreement with previous studies, further indicating that ursolic acid nanoparticle could suppress cervical cancer progression in vitro (55-57). In line with a previous study, our immunofluorescence results suggested that p53 was involved in ursolic acid nanoparticle-inhibited cervical cancer.

Two of the most important members associated with apoptosis in Bcl-2 family include the pro-apoptotic protein Bax and the anti-apoptotic protein Bcl-2 (58). Overexpression of $\mathrm{Bcl}-2$ proto-oncogene damages the therapeutic action of present cancer treatment regimes through apoptosis induction of tumor cells (59). The broad expression of Bcl-2 in different tumors, together with its function in resisting chemotherapy-induced apoptosis, makes bcl-2 a rational target for anticancer therapy $(60,61)$. In addition, inhibitor of apoptosis (IAP) protein families suppress apoptosis within tumor cells (62). The cellular inhibitor of apoptosis protein 1 (cIAP1) has been investigated in regulation of tumor response (63). In the present study, the findings from western blot and immunohistochemistry analyses in vitro and in vivo clearly revealed that the expression of Bcl-2 and cAIP1 were significantly suppressed, but the expression of Bax was highly upregulated, illustrating that ursolic acid nanoparticles showed anti-apoptotic properties during the cervical cancer progression.

In summary, our results indicated that ursolic acid nanoparticles targeted caspases and p53 with downregulation of Bcl-2 and cIAP, inducing apoptosis and leading to cervical cancer cell death. Thus, ursolic acid nanoparticles can be used as a class of antitumor drug development and treatment of cervical cancer for its potential value.

\section{Acknowledgements}

The present study was funded by the Natural Sciences Fund of Shandong, China (ZR2014HL072).

\section{References}

1. Bast RC Jr, Hennessy B and Mills GB: The biology of ovarian cancer: New opportunities for translation. Nat Rev Cancer 9: 415-428, 2009.

2. Phongsavan K, Phengsavanh A, Wahlström R and Marions L: Women's perception of cervical cancer and its prevention in rural Laos. Int J Gynecol Cancer 20: 821-826, 2010.

3. Agarwal SM, Raghav D, Singh H and Raghava GP: CCDB: A curated database of genes involved in cervix cancer. Nucleic Acids Res 39 (Database): D975-D979, 2011.

4. Kawase R, Ishiwata T, Matsuda Y, Onda M, Kudo M, Takeshita T and Naito Z: Expression of fibroblast growth factor receptor 2 IIIc in human uterine cervical intraepithelial neoplasia and cervical cancer. Int J Oncol 36: 331-340, 2010.

5. World Health Organization: International Agency for Research on Cancer: Cervical Cancer - Estimated Incidence. Mortality and Prevalence Worldwide in 2012.

6. Pollier J and Goossens A: Oleanolic acid. Phytochemistry 77: 10-15, 2012.

7. Yang EJ, Lee W, Ku SK, Song KS and Bae JS: Anti-inflammatory activities of oleanolic acid on HMGB1 activated HUVECs. Food Chem Toxicol 50: 1288-1294, 2012.

8. Reisman SA, Aleksunes LM and Klaassen CD: Oleanolic acid activates Nrf2 and protects from acetaminophen hepatotoxicity via Nrf2-dependent and Nrf2-independent processes. Biochem Pharmacol 77: 1273-1282, 2009.

9. Hsu HY, Yang JJ and Lin CC: Effects of oleanolic acid and ursolic acid on inhibiting tumor growth and enhancing the recovery of hematopoietic system postirradiation in mice. Cancer Lett 111: 7-13, 1997.

10. Yamai H, Sawada N, Yoshida T, Seike J, Takizawa H, Kenzaki K, Miyoshi T, Kondo K, Bando Y, Ohnishi Y, et al: Triterpenes augment the inhibitory effects of anticancer drugs on growth of human esophageal carcinoma cells in vitro and suppress experimental metastasis in vivo. Int J Cancer 125: 952-960, 2009.

11. Ngo SN, Williams DB and Head RJ: Rosemary and cancer prevention: Preclinical perspectives. Crit Rev Food Sci Nutr 51: 946-954, 2011.

12. Shishodia S, Majumdar S, Banerjee S and Aggarwal BB: Ursolic acid inhibits nuclear factor-kappaB activation induced by carcinogenic agents through suppression of IkappaBalpha kinase and p65 phosphorylation: Correlation with down-regulation of cyclooxygenase 2, matrix metalloproteinase 9, and cyclin D1. Cancer Res 63: 4375-4383, 2003.

13. Wang X, Zhang F, Yang L, Mei Y, Long H, Zhang X, Zhang J, Qimuge-Suyila and Su X: Ursolic acid inhibits proliferation and induces apoptosis of cancer cells in vitro and in vivo. J Biomed Biotechnol 2011: 419343, 2011.

14. Lin CC, Huang CY, Mong MC, Chan CY and Yin MC: Antiangiogenic potential of three triterpenic acids in human liver cancer cells. J Agric Food Chem 59: 755-762, 2011.

15. Huang CY, Lin CY, Tsai CW and Yin MC: Inhibition of cell proliferation, invasion and migration by ursolic acid in human lung cancer cell lines. Toxicol In Vitro 25: 1274-1280, 2011.

16. Kim KH, Seo HS, Choi HS, Choi I, Shin YC and Ko SG: Induction of apoptotic cell death by ursolic acid through mitochondrial death pathway and extrinsic death receptor pathway in MDA-MB-231 cells. Arch Pharm Res 34: 1363-1372, 2011.

17. Gong YY, Liu YY, Yu S, Zhu XN, Cao XP and Xiao HP: Ursolic acid suppresses growth and adrenocorticotrophic hormone secretion in AtT20 cells as a potential agent targeting adrenocorticotrophic hormone-producing pituitary adenoma. Mol Med Rep 9: 2533-2539, 2014

18. Wang X, Wang Y, Chen ZG and Shin DM: Advances of cancer therapy by nanotechnology. Cancer Res Treat 41: 1-11, 2009.

19. Kreuter J: Nanoparticles - a historical perspective. Int J Pharm 331: 1-10, 2007.

20. Byrne JD, Betancourt T and Brannon-Peppas L: Active targeting schemes for nanoparticle systems in cancer therapeutics. Adv Drug Deliv Rev 60: 1615-1626, 2008.

21. Cho K, Wang X, Nie S, Chen ZG and Shin DM: Therapeutic nanoparticles for drug delivery in cancer. Clin Cancer Res 14: 1310-1316, 2008.

22. Iyer AK, Khaled G, Fang $\mathbf{J}$ and Maeda H: Exploiting the enhanced permeability and retention effect for tumor targeting. Drug Discov Today 11: 812-818, 2006.

23. Talekar M, Kendall J, Denny W and Garg S: Targeting of nanoparticles in cancer: Drug delivery and diagnostics. Anticancer Drugs 22: 949-962, 2011. 
24. Maeda H: Nitroglycerin enhances vascular blood flow and drug delivery in hypoxic tumor tissues: Analogy between angina pectoris and solid tumors and enhancement of the EPR effect. J Control Release 142: 296-298, 2010.

25. Zeng X, Tao W, Mei L, Huang L, Tan C and Feng SS: Cholic acid-functionalized nanoparticles of star-shaped PLGA-vitamin E TPGS copolymer for docetaxel delivery to cervical cancer. Biomaterials 34: 6058-6067, 2013.

26. Mayer B and Oberbauer R: Mitochondrial regulation of apoptosis. News Physiol Sci 18: 89-94, 2003.

27. Danial NN and Korsmeyer SJ: Cell death: Critical control points Cell 116: 205-219, 2004.

28. Suzuki Y, Nakabayashi Y, Nakata K, Reed JC and Takahashi R: X-linked inhibitor of apoptosis protein (XIAP) inhibits caspase-3 and -7 in distinct modes. J Biol Chem 276: 27058-27063, 2001.

29. Kaul R, Mukherjee S, Ahmed F, Bhat MK, Chhipa R, Galande S and Chattopadhyay S: Direct interaction with and activation of p53 by SMAR 1 retards cell-cycle progression at G2/M phase and delays tumor growth in mice. Int J Cancer 103: 606-615, 2003.

30. Brake T and Lambert PF: Estrogen contributes to the onset, persistence, and malignant progression of cervical cancer in a human papillomavirus-transgenic mouse model. Proc Natl Acad Sci USA 102: 2490-2495, 2005.

31. Smith JS, Green J, Berrington de Gonzalez A, Appleby P, Peto J, Plummer M, Franceschi S and Beral V: Cervical cancer and use of hormonal contraceptives: A systematic review. Lancet 361: $1159-1167,2003$.

32. Sasieni P: Cervical cancer and hormonal contraceptives: Collaborative reanalysis of individual data for 16573 women with cervical cancer and 35509 women without cervical cancer from 24 epidemiological studies. Lancet 370: 1609-1621, 2007.

33. Gavrilescu MM, Todosi AM, Aniţei MG, Filip B and Scripcariu V: Expression of bmi-1 protein in cervical, breast and ovarian cancer. Rev Med Chir Soc Med Nat Iasi 116: 1112-1117, 2012.

34. McCredie MR, Sharples KJ, Paul C, Baranyai J, Medley G, Jones RW and Skegg DC: Natural history of cervical neoplasia and risk of invasive cancer in women with cervical intraepithelial neoplasia 3: A retrospective cohort study. Lancet Oncol 9: 425-434, 2008

35. Ikeda Y, Murakami A and Ohigashi H: Ursolic acid: An anti- and pro-inflammatory triterpenoid. Mol Nutr Food Res 52: 26-42, 2008.

36. Andersson D, Liu JJ, Nilsson A and Duan RD: Ursolic acid inhibits proliferation and stimulates apoptosis in HT29 cells following activation of alkaline sphingomyelinase. Anticancer Res 23: 3317-3322, 2003.

37. Ji HF, Li XJ and Zhang HY: Natural products and drug discovery. Can thousands of years of ancient medical knowledge lead us to new and powerful drug combinations in the fight against cancer and dementia? EMBO Rep 10: 194-200, 2009.

38. Xavier CP, Lima CF, Preto A, Seruca R, Fernandes-Ferreira M and Pereira-Wilson C: Luteolin, quercetin and ursolic acid are potent inhibitors of proliferation and inducers of apoptosis in both KRAS and BRAF mutated human colorectal cancer cells. Cancer Lett 281: 162-170, 2009.

39. Hsu YL, Kuo PL and Lin CC: Proliferative inhibition, cellcycle dysregulation, and induction of apoptosis by ursolic acid in human non-small cell lung cancer A549 cells. Life Sci 75: 2303-2316, 2004.

40. Choi BM, Park R, Pae HO, Yoo JC, Kim YC, Jun CD, Jung BH, Oh GS, So HS, Kim YM, et al: Cyclic adenosine monophosphate inhibits ursolic acid-induced apoptosis via activation of protein kinase A in human leukaemic HL-60 cells. Pharmacol Toxicol 86: 53-58, 2000.

41. Cha HJ, Bae SK, Lee HY, Lee OH, Sato H, Seiki M, Park BC and Kim KW: Anti-invasive activity of ursolic acid correlates with the reduced expression of matrix metalloproteinase-9 (MMP-9) in HT1080 human fibrosarcoma cells. Cancer Res 56: 2281-2284, 1996.

42. Liu L, Wu J, Zhang J, Li Z, Wang C, Chen M, Wang Y, Sun, Y, Wang $L$ and Luo C: A compatibility assay of ursolic acid and foodborne microbial exopolysaccharides by antioxidant power and anti-proliferative properties in hepatocarcinoma cells. J Food Agric Environ 10: 111-114, 2012.

43. Wang Y, Cui H, Li K, Sun C, Du W, Cui J, Zhao X and Chen W: A magnetic nanoparticle-based multiple-gene delivery system for transfection of porcine kidney cells. PLoS One 9: e102886, 2014.
44. Delyagina E, Schade A, Scharfenberg D, Skorska A, Lux C, Li W and Steinhoff G: Improved transfection in human mesenchymal stem cells: Effective intracellular release of pDNA by magnetic polyplexes. Nanomedicine (Lond) 9: 999-1017, 2014

45. Wang Y, Cui H, Sun C, Du W, Cui J and Zhao X: Study on performance of magnetic fluorescent nanoparticles as gene carrier and location in pig kidney cells. Nanoscale Res Lett 8: 127,2013

46. Underbrink MP, Howie HL, Bedard KM, Koop JI and Galloway DA: E6 proteins from multiple human betapapillomavirus types degrade Bak and protect keratinocytes from apoptosis after UVB irradiation. J Virol 82: 10408-10417, 2008.

47. Kabsch K and Alonso A: The human papillomavirus type 16 E5 protein impairs TRAIL- and FasL-mediated apoptosis in HaCaT cells by different mechanisms. J Virol 76: 12162-12172, 2002

48. Wang X, Shi Q, Xu K, Gao C, Chen C, Li XL, Wang GR, Tian C, Han J and Dong XP: Familial CJD associated PrP mutants within transmembrane region induced Ctm-PrP retention in ER and triggered apoptosis by ER stress in SH-SY5Y cells. PLoS One 6: e14602, 2011

49. Xu K, Wang X, Shi Q, Chen C, Tian C, Li XL, Zhou RM, Chu YL and Dong XP: Human prion protein mutants with deleted and inserted octarepeats undergo different pathways to trigger cell apoptosis. J Mol Neurosci 43: 225-234, 2011.

50. Virkajärvi N, Pääkkö P and Soini Y: Apoptotic index and apoptosis influencing proteins bcl-2, mcl-1, bax and caspases 3 , 6 and 8 in pancreatic carcinoma. Histopathology 33: 432-439, 1998.

51. Sträter J, Herter I, Merkel G, Hinz U, Weitz J and Möller P: Expression and prognostic significance of APAF-1, caspase-8 and caspase-9 in stage II/III colon carcinoma: Caspase-8 and caspase-9 is associated with poor prognosis. Int J Cancer 127: 873-880, 2010

52. Satoh K, Kaneko K, Hirota M, Toyota T and Shimosegawa T: The pattern of CPP32/caspase-3 expression reflects the biological behavior of the human pancreatic duct cell tumors. Pancreas 21: $352-357,2000$

53. Meggiato T, Calabrese F, De Cesare CM, Baliello E, Valente M and Del Favero G: C-JUN and CPP32 (CASPASE 3) in human pancreatic cancer: Relation to cell proliferation and death. Pancreas 26: 65-70, 2003.

54. Noble P, Vyas M, Al-Attar A, Durrant S, Scholefield J and Durrant L: High levels of cleaved caspase-3 in colorectal tumour stroma predict good survival. Br J Cancer 108: $2097-$ 2105,2013

55. Aylon Y and Oren M: p53: guardian of ploidy. Mol Oncol 5: 315-323, 2011.

56. Murray-Zmijewski F, Slee EA and Lu X: A complex barcode underlies the heterogeneous response of p53 to stress. Nat Rev Mol Cell Biol 9: 702-712, 2008.

57. Blanchette P and Branton PE: Manipulation of the ubiquitinproteasome pathway by small DNA tumor viruses. Virology 384 : 317-323, 2009.

58. Cory S and Adams JM: The Bcl2 family: Regulators of the cellular life-or-death switch. Nat Rev Cancer 2: 647-656, 2002.

59. Youle RJ and Strasser A: The BCL-2 protein family: Opposing activities that mediate cell death. Nat Rev Mol Cell Biol 9: 47-59, 2008.

60. Zhang YX, Kong CZ, Wang HQ, Wang LH, Xu CL and Sun YH: Phosphorylation of Bcl-2 and activation of caspase-3 via the c-Jun N-terminal kinase pathway in ursolic acid-induced DU145 cells apoptosis. Biochimie 91: 1173-1179, 2009.

61. Wensveen FM, Alves NL, Derks IA, Reedquist KA and Eldering E: Apoptosis induced by overall metabolic stress converges on the Bcl-2 family proteins Noxa and Mcl-1. Apoptosis 16: 708-721, 2011.

62. Choi YH, Baek JH, Yoo MA, Chung HY, Kim ND and Kim KW: Induction of apoptosis by ursolic acid through activation of caspases and down-regulation of c-IAPs in human prostate epithelial cells. Int J Oncol 17: 565-571, 2000.

63. Dubrez-Daloz L, Dupoux A and Cartier J: IAPs: More than just inhibitors of apoptosis proteins. Cell Cycle 7: 1036-1046, 2008. 